\title{
PENDEKATAN SCIENCE, TECHNOLOGY, ENGINEERING AND MATHEMATICS (STEM) SEBAGAI ALTERNATIF DALAM MENGEMBANGKAN MINAT BELAJAR PESERTA DIDIK SEKOLAH DASAR
}

\author{
Rika Widya Sukmana \\ PGSD FKIP Universitas Langlangbuana \\ rikasukmana@gmail.com
}

\begin{abstract}
Community service aims to provide insight into knowledge of Science, Technology, Engineering and Mathematics (STEM) approach, to improve professionalism for elementary school teachers at SDN Cilisung 1 and 2, Bandung. In addition, it provides steps how to apply STEM approach for learners through training activities on STEM. The target of the training is elementary school teachers in SDN Cilisung 1 and 2 Bandung. Problems are solved in three stages of activity, namely preparation, implementation and evaluation. Preparation is done by conducting a preliminary survey to see the conditions in the field regarding teachers' professional development. Implementation is done by training, using lecture method that is with presentation technique, followed by practice of micro teaching about STEM. Evaluation of activities carried out for each stage by collecting and summarizing data from each stage of activity. The results of the training activities show the success rate with an indication of material conformity with the needs of SDN Cilisung 1 and 2 teachers, positive responses from the participants, and most participants have understood the STEM approach.
\end{abstract}

Key Words: STEM, Science, Technology, Engineering, Mathematics

\begin{abstract}
ABSTRAK
Penelitian ini bertujuan untuk memberikan wawasan tentang Science, Technology, Engineering and Mathematics (STEM), untuk meningkatkan profesionalisme bagi guru sekolah dasar di SDN Cilisung 1 dan 2, Bandung. Selain itu, bertujuan juga memberikan langkah bagaimana menerapkan pendekatan STEM untuk peserta didik melalui kegiatan pelatihan STEM. Sasaran pelatihan tersebut adalah guru sekolah dasar di SDN Cilisung 1 dan 2 Bandung. Permasalahan dipecahkan dalam tiga tahap aktivitas, yaitu persiapan, implementasi dan evaluasi. Persiapan dilakukan dengan melakukan survei pendahuluan untuk melihat kondisi di lapangan mengenai pengembangan profesional guru. Implementasi dilakukan dengan pelatihan, dengan menggunakan metode ceramah yaitu dengan teknik presentasi, dilanjutkan dengan praktik pengajaran mikro tentang STEM. Evaluasi kegiatan dilakukan untuk setiap tahap dengan mengumpulkan dan meringkas data dari setiap tahap aktivitas. Hasil kegiatan pelatihan menunjukkan tingkat keberhasilan dengan indikasi kesesuaian material dengan kebutuhan guru SDN
\end{abstract}


Cilisung 1 dan 2, tanggapan positif dari peserta, dan sebagian besar peserta memahami pendekatan STEM.

Kata Kunci: STEM, Science, Technology, Engineering dan Mathematics

\section{A. Pendahuluan}

Perkembangan teknologi telah mengubah cara kita berkomunikasi, cara makan, cara bepergian, cara berinteraksi dan sebagainya. Begitu pula dengan cara guru melaksanakan proses pembelajaran. Peserta didik seringkali mengetahui informasi lebih awal dibandingkan dengan gurunya. Oleh karena itu guru dituntut untuk mengikuti perkembangan terkini baik mengenai strategi, pendekatan atau metode dalam proses pembelajaran.

Berdasarkan hal tersebut, lembaga yang bertanggung jawab dalam pengembangan profesi guru dituntut untuk memfasilitasi perkembangan kualitas yang dipertanggungjawabkan secara profesional. Guru professional ditandai dengan beberapa karakteristik sebagai berikut: pemahaman diri, kompeten, memiliki kesehatan psikologis yang baik, dapat dipercaya, jujur, kuat, hangat, responsif, sabar, sensitif dan memiliki kesadaran yang holistik.

Perkembangan global yang pesat akibat kemajuan di bidang teknologi mengharuskan bangsa- bangsa di dunia mengubah sistem pendidikan mereka. Dalam beberapa tahun terakhir, negara-negara maju maupun negara berkembang, berupaya meningkatkan kualitas pendidikan dengan model Pembelajaran Tematik Terpadu (PTP) atau Integrated Thematic Instruction (ITI).

Pembelajaran ini berangkat dari pendekatan tematis sebagai acuan dasar bahan dan kegiatan pembelajaran di mana tema yang dibuat mengikat baik mata pelajaran tertentu maupun antarmata pelajaran. Pembelajaran Tematik ini secara ilmiah telah menunjukkan keberhasilannya dalam memacu percepatan dan meningkatkan kapasitas memori peserta didik.

Science, Technology, Engineering and Mathematics atau disingkat STEM merupakan sebuah pendekatan pembelajaran yang populer di tingkat dunia yang efektif dalam menerapkan Pembelajaran Tematik Integratif karena menggabungkan empat bidang pokok dalam pendidikan yaitu ilmu 
Pendas : Jurnal IImiah Pendidikan Dasar, ISSN Cetak : 2477-2143 ISSN Online : 2548-6950 Volume II Nomor 2, Desember 2017

pengetahuan, teknologi, matematika, dan engineering.

Perkembangan teknologi telah mengubah cara kita berkomunikasi, cara makan, cara bepergian, cara berinteraksi dan sebagainya. Begitu pula dengan cara guru melaksanakan proses pembelajaran. Peserta didik seringkali mengetahui informasi lebih awal dibandingkan dengan gurunya. Oleh karena itu guru dituntut untuk mengikuti perkembangan terkini baik mengenai strategi, pendekatan atau metode dalam proses pembelajaran.

Dua puluh lima tahun yang lalu pernahkah kita berpikir bahwa pekerjaan tukang patri penambal panci akan menghilang karena bahan panci aluminium dihabisi stainless steel. Teller bank dan travel servis juga pelan tapi pasti menghilang. Beli tiket tinggal klik pesan online. Banyak lagi yang siap menghilang dan akan digantikan oleh robot serta kecerdasan artifisial. Siapkah kita dan anak-anak kita? Pendidikan seperti apa yang sebaiknya kita ajarkan? Memang guru tidak tergantikan namun jika cara mengajarnya seperti umumnya saat ini, maka sudah saatnya diganti. Pekerjaan model sekarang punah, akan bermunculan pekerjaan dan profesi baru. Untuk itu siswa perlu dipersiapkan agar kreatif dan inovatif serta memiliki kemampuan untuk beradaptasi.

Sebuah studi dari Redwood Software dan Sapio Research dikeluarkan pada tanggal 4 Oktober 2017 yang mengungkapkan bahwa para pemimpin IT percaya bahwa otomatisasi dapat berdampak pada sektor bisnis sekitar $60 \%$ pada tahun 2022 serta mengancam pekerjaan saat ini. Sebuah laporan terpisah dari PwC, jasa profesional terbesar kedua di dunia, menyarankan garis waktu yang hampir sama; setiap manusia perlu praktek dan mempelajari keterampilan baru, jika tidak maka akan tertinggal karena diambil alih oleh otomatisasi. Otomatisasi mungkin terjadi lebih lambat dari yang kita duga, tapi jelas, bahwa hal ini merupakan tantangan yang akan datang dan perlu dipersiapkan.

Salah satu pendekatan dalam pendidikan yang dapat menjawab tantangan tersebut di atas adalah melalui pendidikan Science, Technology, Engineering and Mathematics (STEM). 


\section{B. Landasan Teori}

STEM merupakan sebuah model pembelajaran yang populer di dunia yang efektif dalam menerapkan Pembelajaran Tematik Integratif karena menggabungkan empat bidang pokok dalam pendidikan yaitu ilmu pengetahuan, teknologi, matematika, dan enjinering. Torlakson (2014:23) menyatakan bahwa pendekatan dari keempat aspek tersebut merupakan pasangan serasi antara masalah yang terjadi di dunia nyata dan juga pembelajaran berbasis masalah (problem-based learning). Pendekatan ini mampu menciptakan sebuah sistem pembelajaran secara kohesif dan pembelajaran aktif karena keempat aspek dibutuhkan secara bersamaan untuk menyelesaikan masalah.

Beberapa manfaat STEM dalam proses pembelajaran diantaranya:

1. Memiliki isu dan masalah dunia nyata dalam hati peserta didik. Dengan ini diharapkan menumbuhkan empati dan mengurangi tawuran.

2. Mengikat peserta didik dengan inkuiri terbimbing dan eksplorasi tertutup terbuka.
3. Secara aktif mengintegrasikan proses desain engineering.

4. Membantu siswa melihat hubungan antara sains dan matematika melalui pengintegrasian konten.

5. Mengharap dan memfasilitasi kolaborasi antar peserta didik, discourse dan kepekaan.

6. Mengundang resiko dengan memulai lingkungan belajar yang mencari lebih dari satu solusi atas setiap masalah.

7. Memahami bahwa kegagalan bagian dari proses dan menghargainya.

Pemerintah, orangtua, guru harus menyadari bahwa dunia pendidikan sangat berubah. Sain, teknologi, enjiniring dan matematika merupakan mata pelajaran yang saling berkaitan dalam kehidupan manusia. Jika dipelajari keempat bidang tersebut saling kait mengait sehingga bisa menjadi bekal bagi peserta didik agar mereka dapat memecahkan masalah dalam dunia kerja, masyarakat serta semua aspek kehidupan mereka di masa yang akan datang.

Dalam rangka menyikapi tantangan yang telah dipaparkan sebelumnya dan pentingnya 
pembelajaran berbasis STEM, Program Studi PGSD berupaya untuk membekali para guru sekolah dasar dengan memberikan materi pembekalan tentang pendekatan STEM.

\section{Metode Penelitian}

Kegiatan pengabdian ini dilaksanakan dalam bentuk suatu pelatihan singkat selama 1 kali pertemuan dengan anggota sebanyak 20 orang guru yang dilaksanakan di SDN Cilisung 1 dan 2 Kabupaten Bandung. Sesi pertama (Tahap Penjelasan) membahas tentang pendekatan STEM dalam tataran teoritis yang meliputi pengertian serta alasan rasional mengapa menggunakan STEM. Sesi kedua (Tahap Simulasi) merupakan pendalaman terhadap materi yang diikuti dengan latihan tentang bagaimana menerapkan pendekatan tersebut dalam kegiatan belajar mengajar. Langkah-langkah pelaksanaan kegiatan adalah sebagai berikut:

1. Tim pengabdian membahas pendekatan STEM dalam tataran teoritis yang meliputi pengertian, langkah-langkah pelaksanaan, serta kelebihan dan kekurangan

dari pendekatan STEM dalam pembelajaran.

2. Tim pengabdian memberikan arahan dan bimbingan kepada guru dalam melakukan simulasi pendekatan STEM dalam mengajar. Para peserta dibagi ke dalam 4 kelompok dengan masing-masing kelompok terdiri atas 4-5 orang peserta.

Tabel 1. Kerangka Kegiatan Pengabdian

\begin{tabular}{|c|c|c|c|}
\hline $\mathrm{N}_{0}$. & Tahapan & Aktivitas & Output \\
\hline 1. & Persiapan & $\begin{array}{l}\text { - Penjajagan lokasi tempat kegiatan } \\
\text { Dan mengurus surat izin serta surat } \\
\text { tugas untuk melaksanakan kegiatan } \\
\text { pengabdian kepada masyarakat. } \\
\text { - Menghubungi Kepala Sekolah } \\
\text { Dasar Negeri Cilisung } 1\end{array}$ & $\begin{array}{l}\text { - Terpilihnya } \\
\text { sekolah dasar } \\
\text { sebagai tempat } \\
\text { pelatihan } \\
\text { - Tersusunnya } \\
\text { jadwal dan } \\
\text { jumlah peserta } \\
\text { pelatihan }\end{array}$ \\
\hline 2. & Pelaksanaan & $\begin{array}{l}\text { - Melakukan kegiatan pelatihan } \\
\text { tentang STEM }\end{array}$ & $\begin{array}{l}\text { - Terlaksananya } \\
\text { kegiatan pelatihan } \\
\text { STEM di SDN } \\
\text { Cilisung } 1 \text { dan } 2 \\
\text { sesuai jadwal } \\
\text { yang ditentukan }\end{array}$ \\
\hline
\end{tabular}

D. Hasil dan Pembahasan

Pelaksanaan kegiatan pengabdian dilakukan pada tanggal 22 Agustus 2017 dari pukul 09.00 sampai 15.00 WIB. Khalayak sasaran pada kegiatan pengabdian ini adalah guru-guru sekolah dasar. Guru-guru yang menjadi sasaran 
Pendas : Jurnal IImiah Pendidikan Dasar, ISSN Cetak : 2477-2143 ISSN Online : 2548-6950 Volume II Nomor 2, Desember 2017

pada kegiatan pengabdian ini yaitu guru-guru SDN Cilisung 1 dan 2 yang lokasi sekolah letaknya berdampingan yaitu sebanyak 20 orang guru.

Secara khusus, kegiatan diprioritaskan untuk memberikan wawasan pengetahuan tentang pendekatan STEM dan cara penerapannya. Adapun pelaksanaan kegiatan pelatihan tentang STEM ini diuraikan sebagai berikut.

1) Tahap Penjelasan atau

Presentasi Tentang STEM

Langkah-langkah kegiatannya sebagai berikut:

a. Merencanakan tempat penjelasan yang disepakati bersama.

b. Penjelasan dan pengantar tentang STEM.

C. Diskusi dan Tanya Jawab.

2) Tahap SimulasiTentang STEM Langkah-langkah kegiatannya dibagi ke dalam 4 sesi:
a. Sesi 1: Mengenal Beruang
b. Sesi 2: Mengenal Volume dan Kubus
c. Sesi
Tuas/Pesawat Sederhana 3: $\quad$ Mengenal
d. Sesi 4: Problem Solving

1. Penjelasan dan Pengantar Tentang Apa Itu STEM

Pada tahap ini peserta pelatihan diberikan materi pengantar tentang apa itu STEM dan mengapa STEM. Penjelasan tentang pengantar STEM dilakukan dengan metode ceramah yaitu presentasi menggunakan powerpoint. Setelah itu dilanjut dengan diskusi dan tanya jawab.

2. Tahap Simulasi tentang
STEM

Tahap simulasi dilakukan setelah tahap penjelasan dan pengantar tentang STEM. Pada tahap ini dibagi menjadi 4 sesi, yaitu sesi mengenal beruang (materi IPA/sains), mengenal volume dan kubus (matematika), mengenal pesawat sederhana (materi IPA/sains) dan terakhir peserta diberikan sebuah masalah yang harus diselesaikan dalam kelompok. Dalam sesi terakhir ini peserta menghasilkan produk. Inilah yang menjadi ciri dan pendekatan STEM, yaitu adanya produk.

Sesi 1:

Peserta melihat tayangan video tentang "Beruang". Setelah melihat tayangan, peserta dalam kelompok 
menyajikan pengetahuan yang mereka peroleh tentang beruang.



Gambar 1. Peserta sedang berdiskusi pada sesi mengenal beruang (materi IPA/Sains)

Setelah itu masuk sesi 2 yaitu materi tentang volume dan kubus (matematika)

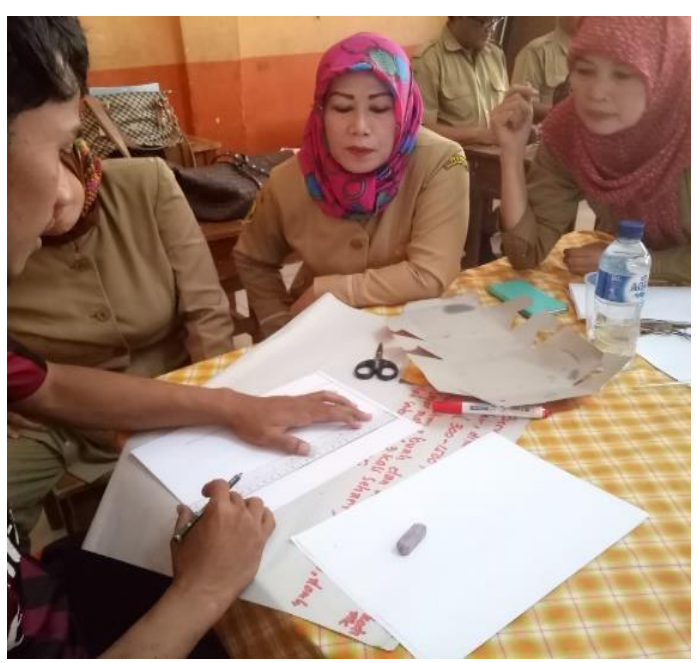

Gambar 2. Peserta sedang berdiskusi membuat kubus dari kertas pada sesi mengenal volume dan kubus (matematika)

Sesi ketiga mengenal pesawat sederhana. Peserta diberi lembar kerja tentang pesawat sederhana.



Gambar 3. Peserta dalam kelompok membuat produk dalam rangka menjawab permasalahan yang diberikan yang diberikan

Pada sesi keempat peserta diberi pertanyaan berupa kasus. Dengan berbekal pengetahuan yang telah diperoleh di sesi-sesi sebelumnya, peserta dalam kelompok diminta untuk memecahkan masalah tersebut.



Gambar 4. Peserta secara

berkelompok mencoba produk yang dihasilkan. 
Berdasarkan pengamatan selama kegiatan pengabdian kepada masyarakat berlangsung, diperoleh beberapa hasil yang positif, diantaranya adalah:

1. Para peserta menunjukkan perhatian yang sangat tinggi terhadap materi pengabdian yang disampaikan oleh tim pengabdian.

2. Para peserta menunjukkan reaksi yang positif terhadap cara menerapkan pendekatan STEM.

3. Para peserta aktif bertanya dan mengungkapkan masalahmasalah yang dialaminya selama ini dan mereka bersemangat untuk dapat menerapkan pendekatan STEM dalam mengajar.

4. Para peserta terlihat kompak dan menjalin kerja sama yang cukup baik dalam latihan tentang penerapan pendekatan STEM.

Ditinjau dari segi materi pengabdian yang disampaikan, banyak pengalaman atau pengetahuan dan keterampilan baru yang diperoleh oleh para guru SDN Cilisung 1 dan 2 Kabupaten Bandung. Sebaliknya bagi tim pengabdian juga memperoleh beberapa input yang bermanfaat tentang berbagai masalah dan kendala yang dialami guru SDN Cilisung 1 dan 2 Kabupaten Bandung dalam kegiatan belajar mengajar di sekolah mereka terutama dalam hal pemilihan strategi atau pendekatan maupun model pembelajaran. Semua pengalaman tersebut dapat tim pengabdian gunakan sebagai bahan pertimbangan untuk melaksanakan pengabdian kepada masyarakat di masa-masa yang akan datang.

Testimoni dari para peserta pelatihan STEM dapat dilihat di link youtube berikut ini:

1. https://www.youtube.com/watch ?v=DQxI2PYbRpk

2. https://www.youtube.com/watch ?v=e6LKKdqli6g

3. https://www.youtube.com/watch ?v=tb nos5i40l

\section{E. Kesimpulan}

Berdasarkan uraian yang telah dikemukakan pada bagian sebelumnya, diperoleh kesimpulan bahwa kegiatan pengabdian kepada masyarakat ini dapat meningkatkan pengetahuan dan keterampilan guruguru di SDN Cilisung 1 dan 2 
Kabupaten Bandung tentang

pendekatan STEM dalam

pembelajaran, meningkatkan

semangat guru-guru SDN Cilisung 1

dan 2 Kabupaten Bandung untuk memberikan pelayanan yang terbaik kepada para siswa.

Berdasarkan kepada hasil yang diperoleh maka dapat disarankan beberapa hal sebagai berikut:

1. Berdasarkan permintaan dari peserta, hendaknya kegiatankegiatan seperti ini dapat ditingkatkan frekwensi pelaksanaannya.

2. Biaya untuk pelaksanaan kegiatan ini hendaknya lebih ditingkatkan, sehingga dapat melaksanakan kegiatan lebih variatif dan waktu lebih lama dengan melibatkan lebih banyak peserta.

\section{DAFTAR PUSTAKA}

Anonim (2005), Undang-Undang SISDIKNAS 2003, UU RI No. 20 Tahun. 2003, Cet. ke-2 .Jakarta: Sinar Grafika.

Anonim (2006), Undang-undang Guru \& Dosen. UU RI No. 14 Thaun 2005. Jakarta: Sinar Grafika. 